\title{
Where Else Have You Been? The Effects of Diaspora Consciousness and Transcultural Mixtures on Ethnic Identity
}

\author{
Niranjala D Weerakkody \\ Faculty of Arts, Deakin University, Geelong, VIC, Australia
}

\author{
nina.weerakkody@deakin.edu.au
}

\begin{abstract}
In social science research, the demographic categories of ethnicity are linked to what the census bureau considers as a person's ethnic heritage. However, these categories are based on the societal assumption that members of a given category share the same characteristics and life experiences, even though the heterogeneity between members within a category may be as diverse as between categories.

The paper examines the 15 interview subjects of a research study drawn from 10 minority migrant groups, where seven of them indicated significant transcultural experiences before migrating to Australia. It argues that their lived experiences and subjectivity vary from others who migrated directly from their native countries. The formers' diaspora consciousness and transcultural mixtures may introduce an artifact to a research study's design, affecting the validity of the data collected. The paper examines other situations where this anomaly can occur and proposes precautions to minimize its negative effects.
\end{abstract}

Keywords: Demographic categories, ethnic identity, cultural identity, diaspora consciousness, transcultural mixtures, ethnic minorities, validity of research data, cultural identification, confounding variables, qualitative research.

\section{Introduction}

"The problem of origin ... (is) no longer a question of starting or finishing. The question (is) rather what happens in between” (Deleuze, 1995, p. 121).

"The effect of mass migration has been the creation of radically new types of human beings: people who root themselves in ideas rather than places, in memories as much as in material things- because they are so defined by others- by their otherness. (For) people in their deepest selves, strange fusions occur ... unprecedented unions between what they were and where they find themselves. The migrant suspects reality. Having experienced

Material published as part of this publication, either on-line or in print, is copyrighted by the Informing Science Institute. Permission to make digital or paper copy of part or all of these works for personal or classroom use is granted without fee provided that the copies are not made or distributed for profit or commercial advantage AND that copies 1 ) bear this notice in full and 2) give the full citation on the first page. It is permissible to abstract these works so long as credit is given. To copy in all other cases or to republish or to post on a server or to redistribute to lists requires specific permission and payment of a fee. Contact Publisher@InformingScience.org to request redistribution permission. several ways of being, he (sic) understands their illusory nature. To see things plainly, you have to cross a frontier” (Salman Rushdie, 1991, p. 24).

Between 1965 and 2000, the number of people moving from their native country to others as legal migrants had doubled from 75 million to 150 million (IOM, 2000). The 'classical countries of immigration' receiving the bulk of this num- 
ber since the late 1940s are the USA, Canada, Australia, New Zealand and Argentina. Since the 1980s, southern European countries such as Greece, Italy and Spain have moved from being emigration to immigration areas. The globalization of migration has seen a diversification of areas of origin as well as receiving countries for migrants, resulting in a broad spectrum of economic, cultural and social backgrounds being represented by these new immigrants (Castles \& Miller, 2003). Generally, such migrants will report their ethnic identity by their national or ethnic origin. International and local census bureaus as well as social researchers will classify them under fairly wide demographic categories under ethnicity or national origin. These migrants also make up the official minority groups in their receiving countries.

Julie Andsager (2001; p. 1) argues that when categorizing all those born between 1946 and 1965 as 'Baby Boomers' or lumping together all those over 65 years of age for the purpose of research, we are oversimplifying a demographic variable, based on certain societal assumptions. Such categorizations assume that all those belonging to the category share the same characteristics and life experiences. This situation is the same for minority groups in multicultural societies where people are categorized based on their ethnic identity alone, assuming that all members within each group are alike and have undergone the same or similar life experiences. For examples, since the events of September 11, 2001, Muslims worldwide find themselves so categorized, profiled and negatively stereotyped which has proven extremely problematic and a disadvantage to them. This assumption also applies to other demographic categories such as gender, class and race. In an era of globalization where people move around the world as refugees, guest workers, tourists, students and migrants as part of ethnoscapes (movement of people) (Appadurai, 1990), their ethnic or national identity alone will not indicate the various life experiences gained in different countries other than the one of their birth, migration and settlement, causing heterogeneity of characteristics between members of the same ethnic group. Such assumptions of homogeneity pose problems for the validity of the category of 'ethnicity' in social science research (Kirk \& Miller, 1991), when collecting data from individuals identifying themselves as belonging to a particular ethnic group. This is because there is probably a broader range of characteristics and cultural ambiguity represented by individuals within groups than between groups (Kaplan, 1973). Therefore, one needs to recognise that the socially constructed demographic variables such as ethnic identity or ethnic group membership, may impose differences between people where none may exist (eg. Children born in Australia and socialized as Australians but still categorized under their parents' ethnicity instead of as 'Australians') or impose homogeneity when it is not really so (eg. Categorising all those as belonging to Chinese ethnicity irrespective of their country of origin- such as Singapore, Malaysia, China and Hong Kong, with different social, cultural, economic and political systems and historical realities experienced by those individuals). Therefore, sub categories may be needed to understand and acknowledge these differences (Andsager, 2001; p. 8) to account for the anomalies where a migrant may have lived in a third or even a fourth country before their arrival in Australia as a migrant. Failing to address or at least acknowledge such anomalies and heterogeneity of characteristics within group members can introduce 'artifacts' (confounding or an extraneous variables) to a research design, which can contaminate the findings and affect the internal validity (Wimmer \& Dominick, 2006) or accuracy of the data collected.

Demographic categories represent products of socialization (as being of a particular ethnic group even though a person may have never lived in what that ethnic group considers as their mother land). Therefore, it will be useful to discern individual traits and life experiences of group members instead of reifying stereotypical explanations or demographic categories set out in society (Andsager, 2001; p. 8). It is also necessary to avoid the unquestioned acceptance of self reported ethnic identities of research participants, when conducting social science or communication research with ethnic minority members. 


\section{Background}

In 2000, the author conducted 15 depth interviews with individuals identifying themselves as members of the ten largest ethnic minority groups in a regional city in Australia during the preliminary stage of a research project that examined how people who are members of minorities frame their discourses when talking about the majority and other minorities, while discussing their experiences of living in Australia as migrants and members of minority ethnic groups. The project being funded by a research grant, allowed for an honorarium of $\$ 50$ to be paid to each interviewee as an incentive to participate in a 1-2 hour depth interview. The latest census data (from 1996) for the city were used as the operational definition (Wimmer \& Dominick, 2006) to identify its 10 largest ethnic groups and the 15 subjects were chosen to proportionately represent them in a stratified sample. The sample consisted of eight (8) females and seven (7) males belonging to various age groups. The ten ethnic groups which qualified as the largest in the city and the number of subjects chosen from each group based on their proportion in the population, were three Italians and two Russians and one each from those identifying themselves as Croatian, Chinese, Cambodian, Greek, Serbian, Polish, Spanish, German/Austrian, Czechoslovakian and Dutch. The author also endeavored to recruit interviewees who had arrived in Australia during different decades to obtain a mix of subjects and selected individuals previously unknown to her.

A call for volunteers was sent to the local Ethnic Communities Centre for posting on their notice board. The various social clubs and associations of the selected ethnic groups in the area were identified with the help of the local telephone directory and were contacted and requested to help the author in publicizing the call for volunteers. Many colleagues and contacts of the author helped distribute the advertisement by passing it on to members of the relevant ethnic groups of their acquaintance.

In response to the advertisement, many individuals telephoned to express their interest. The author noted their declared ethnic identity, age, when they arrived in Australia, and their sex and selected the 15 participants to meet the specifications of the sample. In some cases, participants helped locate other suitable individuals from among their acquaintances, when suitable volunteers from a particular ethnic group had not responded to the advertisement or had done so in insufficient numbers.

Before the interviews, the author contacted each subject about twice over the phone to collect their basic information and to schedule the interviews. Of the 15 interviewees, three were conducted at the author's workplace, and the others at the subjects' residences. Before each interview, the author made small talk with the interviewee to put them at ease in talking to a stranger about their life experiences and opinions. The purpose of the interview and the rights of the subjects were explained to them via a Plain Language Statement and a Consent Form, required and approved by the Ethics Committee of the author's organization.

The author used a semi-structured interview protocol or a set of questions, which asked the interviewees to state where they were born and when and how they arrived in Australia, before requesting them to express their opinions about their life experiences as migrants in Australia. However, in the process of answering these questions, it became apparent that seven (7) of the 15 participants had lived part of their lives outside the country of their birth, the one identified as their original nationality or the one linked to their ethnicity.

The details of these seven participants are as follows:

Subject No. 3: Female, 70 years of age.

Ethnic identity declared as Chinese. Born in Bendigo, VIC, Australia in 1930 and lived in Australia her entire life. Is a descendent of Chinese immigrants of the gold rush era and the secretary of the Chinese Cultural Association in the city. 
Subject No. 4: Male, born in 1959.

Cambodian ethnicity. Arrived in Australia in 1999 and is a survivor of 'the killing fields'. Lived in Cuba from 1982-1988 undergoing tertiary study on a Cuban government scholarship. Speaks French, Spanish and English fluently.

Subject No. 5: Female, age 33 years.

Born in Yugoslavia (today’s Serbia) and identifies as of Serbian ethnicity. Arrived in Australia in 1999 (only 7 months in Australia at the time of the interview). Lived in Serbia with her grandparents but visited her parents who were guest workers in Switzerland during school holidays. Parents have been living in Switzerland for 30 years. Married to a Serbian-Australian she met in Serbia.

Subject No. 6: Female, Age 76 years.

Identifies herself as Italian. Born in Egypt in 1924 and migrated directly to Australia in 1955. Never lived in Italy but learnt Italian, French and English in school and speaks Italian as her first language.

Subject No. 11: Male, Age 64 years.

Born in Spain and identifies as Spanish. As a teenager, moved to Switzerland and then to Germany where he lived and worked until the age of 33, when he migrated to Australia.

Subject No. 13: Female, age 40 years.

Lithuanian ethnicity. Married a Polish person and lived in Poland for two years before migrating to Australia with him at the age of 22. Considers herself as one on the 'young' Polish migrants in the city as the others are either Australian-born or arrived in Australia 40-50 years ago.

Subject No. 14: Female, born in 1949.

Identifies as Russian but was born in China. Lived in a segregated and self-sufficient (White) Russian community in Mongolia. Grandparents moved to China to live in exile in 1922 after the Russian Revolution of 1917. Lived in China till she was 14 when they migrated to Australia in 1963. Visited Russia as a tourist a few years ago. Never lived in Russia but is fluent in Russian and teaches the language to the children of her local Russian community.

\section{Issues of Validity in Social Science Research}

Validity refers to the degree to which a measure taps into what we think it is measuring (Adler \& Clark, 2003; p. 150). But Cope (2004) points out the contentious and unresolved nature of the issue of 'rigor'- especially in qualitative research, in terms of validity and reliability (p. 5) of the data collected. Therefore, any social science researcher should anticipate and be aware of the challenges that may arise in relation to issues of validity in one's research projects (Cope, 2004). It is quite accepted that a researcher brings his or her subjectivity based on one's own background (Burns, 1994), and that his or her subject position (in society as either powerful / dominant or powerless /marginalized) and self-reference (autobiography or life experiences) come into play when interpreting and collecting data in a qualitative research process, which provides a context to the findings (Cope, 2004; p. 8). This would be the same for research subjects when they express their views and opinions, which are colored by their own unique and even idiosyncratic life experiences, which can in no way be anticipated before the research commences. For example, the three Italian subjects selected for the preliminary study were very different from each other as one was born in Italy and migrated to Australia in the late 1940s as a young man, while another was a 76 year old born and living in Egypt before arrival in Australia in 1955. She had never visited Italy before migrating to Australia. The third Italian was in his early 30s, was born and lived 
his entire life in the same city in Australia and speaks English as his first language. This indicated the heterogeneity of the three subjects and their life experiences, even though they claimed to have the same ethnic identity.

\section{Stratified sampling}

According to Wimmer \& Dominick (2006) and Baxter \& Babbie (2004), stratified sampling - the procedure used in this study to select the interview subjects based on census figures for the various ethnic groups, was expected to ensure that the sample was drawn from a homogeneous subset of the population (the ethnic minorities living in this city) that has similar characteristics. Homogeneity is considered to help reduce sampling error. According to Daymon and Holloway (2002), 'The members of a sample (e.g. drawn from the same ethnic group) generally share certain characteristics and experiences which are important for the development of the study' (p. 159). Had this study in question been the project proper involving a much larger number of subjects instead of being a preliminary one where only a few or only one subject was chosen to be interviewed from each ethnic group, the sample would have ended up being heterogeneous for each ethnic group without the researcher realizing it until after a good number of the interviews had been completed.

\section{Validity and theory}

Kirk and Miller (1991) argue that all measurements are to the same degree suspect and the issue of validity (accuracy) is a fundamental problem of theory- in this case the assumption that those belonging to the same ethnic group or demographic category will be homogeneous in their characteristics and life experiences. A theory may assert that a measurement may be valid under all circumstances when in fact it may not. In other words, the question of repeatable regularities will be an issue to be kept in mind with validity of interview data collected from members of demographic groups (Kaplan, 1973; p. 67) as they can be heterogeneous in characteristics within the group, as much as between groups. Therefore, in social science research, the issue of validity is a question of whether the researcher sees what he or she thinks he or she sees (Kirk \& Miller, 1991; p. 21).

\section{Identity}

The concept of identity, as linked to the modernist understanding of the world is that it is singular and unitary. But the postmodern view argues that identities are multiple, complex and continuously changing (Grieshaber \& Canella, 2001). Identities are also linked to society, power and circumstance, which in turn are linked to a person's lived experiences, which are shaped by their various group memberships based on gender, ethnicity, religion, class, race, sexual orientation, nationality, education, occupation etc., which result in multiple lived experiences (Canella \& Grieshaber, 2001). Postmodernism highlights the historical, political and societal grounding of individuals and groups, which recognizes the complex nature of individuals as members of complicated, heterogeneous societies, giving us an opportunity to examine individuals and groups in their wider discourses and less confined identities (Canella \& Grieshaber, 2001; p. 173).

Identity provides us with a location in the world and presents the link between us and the society in which we live, and provides a conceptual tool with which to understand and make sense of social, cultural, economic and political changes (Woodward, 2003; p. 1). But 'identity is never a static location and contains traces of its past, and what it is to become. It is a contingent, a provisional full stop in the play of differences and the narratives of our own lives' (Rutherford, 1990; p. 24). 
Identity examines how a person fits in (belongs) to the community and the social world and is the interface between one's subjective positions and social cultural situations (Woodward, 2003). It gives a person a sense of personal location (Weeks, 1990). Identity tells us who we are and how we relate to others and the world we live in. Identity tells us how and in what ways we are the same as or different from others (Woodward, 2003; p. 2). Identities are not neutral because when saying who we are, we also indicate what we believe and what we desire, which may be in conflict between different communities as well as within individuals themselves (Weeks, 1990; p. 89).

Gilroy (2003) argues that even though race, ethnicity and nationality may seem to appear to offer a secure sense of identity, it is illusionary and problematic because due to its rigidity and constraints involved in establishing absolute and fixed divisions between peoples. Identities of persons are communicatively constituted in two senses- discursively and interactively (Mokros, 1996).

\section{Issues of Cultural/Ethnic Identity}

Identity is complex and multifaceted- especially in relation to diaspora identities. Therefore, conceiving national or ethnic identities as fixed, closed, and unchanging, has negative consequences (Gilroy, 2003; p.303). Identity and culture are shaped by common historical experiences and memories (Smith, 1990). Cultural identity on the other hand is one's sense of belonging to a given society or to the global cultural supermarket (Matthews, 2000). It is also the 'identification with a group that has shared systems of symbols and meanings as well as norms and rules for conduct' (Collier \& Thomas, 1988; p 188).

A key factor in cultural identity is national identity. Most people today are socialized and propagandized to hold a national or cultural identity (eg. Protecting our way of life, values etc.). But national cultural identity is eroded by the cultural supermarket with globalized mass media and multinational corporations such as McDonalds, contributing towards homogenizing of our cultural experiences (Matthews, 2000). Under the postmodernist view, 'Identities are ...points of temporary attachments to the subject positions which discursive practices construct for us' (Hall, 1996; p. 6). According to this definition, identities are not fixed. Anthony Giddens defines identity as 'how the self conceives of itself and labels itself (Giddens, 1991; p 53).

Some researchers argue that cultural identities are studied in the absence of consistent categories for defining various types of cultural communities, which are based on arbitrary categories of classification used differently by different scholars to define different groups as cultural communities. These parameters include nationality, ethnicity, race, gender, social class, 'subculturalism', and oganizational systems (Belay, 1992).

The three main features contributing to cultural identity are: temporality (as historically emergent and evolved through time, a shared history of the group handed down through generations); territoriality (claimed and linked to a territory); constrastivity (collective consciousness and contrasting themselves against other groups); interactivity (cultural identity as created through social interaction and being enduring and resistant to change); and multiplicity (an individual having a variety of identities such as ethnicity, race, gender, and class.) (Belay, 1996).

Belay (1996) also discusses the impact of globalisation on cultural identity as part of global and international interactional processes and the challenges and opportunities posed due to the growing interconnectedness and interdependence between nations in the negotiation of identities. These multidirectional shifts of cultural identification result in tensions and transformations (p. 320). Globalisation has exposed individuals, communities and nations to diverse 'interactional conditions of utmost cultural ambiguity', which they are ill prepared or unable to handle, that it may lead people to seek the security of their ethnicity or religion such as some migrants holding 
on to their own, without integrating into the new culture. At the same time, the new globalized interactional context can lead to a withering away of certain types of cultural identity (Belay, 1996; p. 320).

Globalization also introduces new territorialities and temporalities to cultural identity. They in turn influence contrastivity, interactivity and multiplicity in individual identities. Exposure to multiple 'others' in a globalized world (say via travel or while living in another country), may contribute to individuals becoming less parochial and able to compare and contrast one's identity with those of others and be able to understand the concepts of 'self' and 'others' better. This means that interview subjects who were exposed to other cultures may interpret and understand their life experiences in Australia in a manner different from those who had not been exposed to other cultures before coming to Australia.

\section{Types of cultural identification}

Cultural identity is how people culturally construct and present themselves (Matthews, 2000; p. 122). Many scholars have argued the ambiguities of the categories used in the classification of various cultural communities in the research literature. For example, Asian Australians may come from a variety of countries with diverse cultural, ethnic, racial, linguistic, religious and social systems. At the same time, the English, Scottish and Welsh (migrants in Australia) are classified as a single group for census purposes as coming from the United Kingdom (Belay, 1996). This leaves

no room for other categories of classification such as Indian- Australians who may come from the different states in India with diverse cultural characteristics and identities.

Belay (1996) introduces the six types of cultural identities evident in today's global interactional processes. They are: sociological (based on demographics, including religion, sexual orientation, disabilities etc.); occupational (linked to formal occupations and related institutions); geo-basic (related to cultures that evolved in different geographic regions such as Asia and Africa, assuming common cultural legacies that predates nations and based on racial characteristics); national (the most powerful parameter of cultural identification and linked to legally defined rights and responsibilities of citizenship); co-cultural (multiracial nations that represent different geo-basic groups but belong to the same nation such as the USA or Australia); and ethnic (designating a variety of collectivities within a larger national culture) (p. 325).

\section{Ethnic identities}

Used often in everyday language, the term 'ethnic identity' creates complications when used in academic contexts, with reference to studying cultures and cultural identification (Belay, 1996). This is because, the term is used to label a variety of collectivities within a large national culture, including 'racial groups', minorities and immigrant groups- which can mean either everything or nothing at all (Cohen, 1993; Jaipaul, 1977). Belay (1996) uses the term 'ethnic identity' to refer to sub-national groups in 'racially' homogeneous societies as opposed to geo-basic and cocultural identities where ethnic identification is not related to differences in physical characteristics. He sees ethnic identity as based on cultural elements such as community, physical contiguity, religious affiliation, language / dialect, and blood or kinship relationships among members. These different classifications indicate how the demographic categorization of ethnicity generally used in census and research contexts can be problematic and inadequate to represent the heterogeneity of research subjects used to study various phenomena in multicultural societies. Ethnic identity is generally based on the idea of particular people belonging to a particular place (eg. A particular province of a country) and can also become an adjunct to one's existing national identity or serve as a counterforce to national identity (Matthews, 2000; p. 9). 


\section{Diaspora, Diaspora Consciousness and Transcultural Mixtures}

A diaspora results in the scattering of people due to war, oppression, poverty, enslavement, indenture, pogroms, genocide and the search for better economic and social opportunities (via migration), which results in opening the diaspora culture to new influences and pressures. These new influences will vary based on where they 'scatter' in their search for a 'haven' or a new location to settle. Diaspora as a concept offers new possibilities for understanding identity to visualize a future to form social solidarity not necessarily determined by place or nationality (Gilroy, 2003; p. 304).

\section{Diaspora Consciousness}

Diaspora Consciousness is reproduced when identity is focused on the social dynamics of remembrance and communication, linked to a strong sense of the dangers involved in forgetting the location of one's origin and the process of diaspora or 'scattering' (Gilroy, 2003; p. 318). Members of a diaspora could end up with a mix or hybrid or even a recombination of cultures and identities, with aspects retained from its 'parent' culture. This would be called a Transcultural mixture. Texts such as narratives of their life experiences (eg. given during interviews) of these hybrid individuals should be seen as complex, compound formations and observed in terms of the durability of their original culture and identity. In other words, one should consider the experiences of these migrants or members of a diaspora who had been exposed to other cultures as different from those who were not (Gilroy, 2003).

\section{Transcultural Mixtures}

Transcultural mixtures alert us to the language/s, cultures and everyday life experiences these migrants may have been exposed to during some part of their life or time spent 'in transit' before moving to Australia from their original countries. Transcultural mixtures also tell us to recognize the changes or metamorphoses undergone by individuals who may claim a particular national or ethnic identity, due to their various lived experiences. Identity is the compound result of many accretions. Its protean (changes in shape randomly and continuously) constitution is not under the control of ethnic, racial, cultural or national absolutism (Gilroy, 2003; p. 323). However, like the (White) Russian subject in the study who grew up in a segregated Russian community while living in China, a person can be considered to have been able to maintain their culture in a form frozen at the time of their community's exile from Russia, without being mixed or influenced by the Chinese/Mongolian culture of their hosts. However, this would be a unique situation, which would have been possible only within the context of the Cold War, where her Russian community had been protected (according to the interviewee, presumably by both the US and Chinese governments) and allowed live in that location under special circumstances due to the political nature of their exile.

\section{Not 'peas in a pod'}

The concepts of diaspora consiousness and transcultural mixtures highlight the issue of sameness within differentiation and differentiation within sameness. It argues against the assumption that political and cultural identity can be described and understood with the analogy of the indistinguishable 'peas in a pod'. Apart from sharing a common genealogy and geography, members subscribing to a common ethnic or national identity who are part of a diaspora, may find that the pressure to associate, remember or forget their original culture may vary with the changes they face within the political and economic environment the members of the diaspora live in, which creates differences between members' lived experiences (Gilroy, 2003; p. 332). For example, liv- 
ing in an environment where one is free or not free to practice one's original culture or religion would influence how strongly the members would want to practice or preserve it or how easy or difficult it will be for them to maintain it.

\section{Discussion}

This paper argues that the varying life experiences of subjects who belong to the same ethnic group or claim the same ethnic or national identity can create an artifact or introduce a confounding variable to a study design, due to their heterogeneous nature, individual characteristics, and diverse lived experiences, within the sample. The way to control this shortcoming would be to be aware of the phenomenon that not all migrants from the same ethnic or national group will have the same life history. Therefore, a researcher must endeavor to seek information on their life experiences before recruiting them for a study. Thereafter, individuals can be recruited to make the sample as homogeneous as possible. In other words, internal validity of the data can be guarded by controlling the 'artifact' or confounding / extraneous variables, of not having subjects who are too different from each other in terms of their life experiences or are comparable to each other. It will also help rule out the alternative explanations based on the natural differences among people. This may be achieved by a) randomizing the sample, b) 'matching' (making sure subjects with the confounding variable are chosen along with ones that do not) or c) by incorporating the confounding variable into the study design (Wimmer \& Dominick, 2006; p. 139).

\section{Controlling the Confounding Variable}

Randomization may not be possible in some research studies with ethnic minorities, due to the inability of the researcher to reach the entire population of the required ethnic minority group members in the research location /city and / or due to the English language skills required of the interview subjects as not all ethnic minority members- especially the older ones lack fluency in the language. Using interpreters and translators for interviews conducted with non-English speaking subjects may not always be affordable to a researcher without the required funding. Matching of the confounding variable may be carried out in two ways. It may be achieved with constancy where the variable is made uniform to all subjects. eg. Select subjects who had all been living in third countries at least for X number of years, before arriving in Australia / were born in Australia to migrant parents but had not lived anywhere else for more than two years / had arrived in Australia directly from their native country etc. The other method is matching by pairing. This could be done by matching a subject of a given ethnic group who has come straight to Australia from one's own country with one who has spent time in a third country before their arrival in Australia. (This had already been achieved with the Italian group in the study where one was born in Italy and arrived in Australia in the 1940s, the other was born in Egypt and never lived in Italy, and the third was born and raised in Australia by Italian migrant parents.) However, matching by constancy limits the generalizability of the findings and restricts the size of the population available for sampling. Both forms of matching require some prior knowledge about the subjects (Wimmer \& Dominick, 2006; p. 139).

\section{Improving Validity}

The third option for improving the validity of the data collected will be to include the confounding variable in the research design. This method helps control the impact of the artifact or confounding/extraneous variable by using it as an independent variable in the study. For example, choose a subject for each of the selected ethnic groups who had lived in a third country before migrating to Australia. However, this process will increase the costs and time taken for the study by increasing the number of subjects required for interviewing. 


\section{Conclusion}

The narratives of members of diasporas such as migrants in Australia, indicate the complex nature of a person's national, ethnic or cultural identity, which are far different from the old views based on religious, racial, national and ethnic identities. This preliminary study with only 15 subjects indicates that even migrants who arrived in Australia in the 1940s and 1950s may have voluntarily lived in third or even fourth countries, contrary to the belief that ethnoscapes are a phenomenon of the global village or globalization of the 1970s and beyond. With the Middle East, Southern Europe and Africa attracting guest workers from Asia, who later decide to migrate to the classical migrant countries such as Australia, New Zealand, the USA and Canada, the effects of diaspora consciousness and transcultural mixtures on research involving ethnic minorities will remain a factor for qualitative as well as quantitative researchers, who will continue to use the official categorizations for ethnic groups set by census bureaus and social research groups in these countries.

\section{Heuristic Value of the Study}

The findings of this study also has heuristic value (Littlejohn, 2002) in the sense that the findings and the theorizing about the limitations of the demographic category of ethnicity in social science research can be extended and applied to research and theorizing in the discipline of education and communication involving ethnic minority students as well as international students. Most Australian universities today enroll a significant number of ethnic minority students who may be either born overseas or in Australia to migrant parents and currently are Australian citizens or permanent residents. They may be inadvertently categorized by their original nationalities for purposes of research and official statistics. They too may have been living in third countries such as in the Middle East, Africa or even the West where their professional parents worked as guest workers, before migrating to Australia.

Anecdotal evidence also suggests that many international students currently studying in Australia are in reality those who grew up in third countries such as in the Middle East or Africa, where their parents worked as professionals or guest workers, which actually made it more affordable or even possible for them to study overseas in the first place. Even though these students may carry passports of their country of birth or the original country of their parents, they would have spent little time in their 'native' countries. Such students will be officially categorized under their legal nationality even though they will possess the characteristics of transcultural mixtures and will be different from students who arrive directly from their native countries as international students having been born, raised and undergone their secondary education in their native countries.

Therefore, any researchers carrying out studies involving ethnic minority or international students in Australia, (or Argentina, Canada, New Zealand and the USA for that matter), will need to be aware of this phenomenon.

In conclusion, this paper would argue that the demographic categorisation used for grouping ethnic minorities or migrants in Australia may be inadequate as they can include heterogeneous individuals who indicate differences within a category as much as between categories due to their diverse lived experiences, which serve as artifacts or confounding or extraneous variables to social science research studies, involving ethnic minorities.

Note: This paper is based on a research study funded by a Priming Grant from the Faculty of Arts at Deakin University, VIC, Australia, where the author served as Chief Investigator of the project. 


\section{References}

Adler, E. S. \& Clark, R. (2003). How it is done: An invitation to social research, (2nd edition). Belmont, CA: Wadsworth-Thomson.

Andsagar, J. (2001). Defining individual differences in research. CTM Concepts-The Newsletter of the Communication Theory and Methodology Division of the AEJMC, 29(2), Spring, 1, 8.

Appadurai, A. (1990). Disjuncture and difference in the global cultural economy, Public culture, 2(2), Spring, 1-24.

Baxter, L. A. \& Babbie, E. (2004). The basics of communication research. Belmont, CA: WadsworthThomson.

Belay, G. (1992). Conceptual strategies for operating multicultural curricula, Journal for Library and Information Science, 33, 295-306.

Belay, G. (1996). The (re)construction and negotiation of cultural identities in the age of globalization. In H. B. Mocros (ed), Interaction and identity: Information and behavior (Vol. 5, pp. 320-346). New Brunswick, NJ: Transaction Publishers.

Burns, J. (1994). Extending critique within phenomenography. In R. Ballantyne \& C. Bruce (Eds.), Proceedings of phenomenography: Philosophy and practice (pp. 71-76). Brisbane, QLD: Queensland University of Technology Publications and Printing.

Canella, G. S. \& Grieshaber, S. (2001). Identities and possibilities. In S. Grieshaber \& G. S. Canella (Eds.), Embracing identities in early childhood education: Diversity and possibilities (pp. 173-187). New York: Teachers' College Press.

Castles, S. \& Miller, J. M. (2003). The age of migration: International population movements in the modern world (3rd ed.). New York: Pelgrave Macmillan.

Cohen, A. P. (1993). Culture as identity and intercultural communication. In L. A. Samovar \& R. E. Porter (Eds.), Intercultural communication: A reader (pp. 36-44). Belmont, CA: Wadsworth Publishing Company.

Collier, M. J. \& Thomas, A. (1980). Cultural identity: An interpretive perspective. In Y. Y. Kim \& W. B. Gudykunst (Eds.), Theories in intercultural communication (pp. 99-122). Newbury Park, CA: Sage.

Cope, C. (2004). Ensuring validity and reliability in phenomenographic research using the analytical frameworks of a structure of awareness, Qualitative Research Journal, 4(2), 5-18.

Daymon, C. \& Holloway, I. (2002). Qualitative research methods in public relations and marketing communications. London: Routledge.

Deleuze, G. (1995). Negotiations 1972-1990. (Trans. M Joughlin), New York: Columbia University Press.

Denzin, N. (1970). Sociological methods. Chicago, IL: Aldine.

Giddens, A. (1991). Modernity and self-identity: Self and society in the late modern age. (pp. 53-54). Stanford, CA: Stanford University Press.

Gilroy, P. (2003). Diaspora and the detours of identity. In K. Woodward (Ed.), Identity and difference. (pp. 301-342). London: Sage.

Gireshaber, S. \& Canella, G. S. (2001). From identity to identities: Increasing possibilities in early childhood education. In S. Grieshaber \& G. S. Canella (Eds.), Embracing identities in early childhood education: Diversity and possibilities (pp. 3-22). New York: Teachers' College Press.

Hall, S. (1996). Introduction: Who needs identity? In S. Hall \& P. du Gay (Eds.), Questions of cultural identity (p. 6). London: Sage.

IOM (2000). World migration report 2000. Geneva: International Organisation for Migration.

Jaipaul, A. (1977). Politics of ethnicity. Philadelphia, PA: Ethnic Heritage Affairs Institute. 
Kaplan, A. (1973). The conduct of inquiry: Methodology for behavioural sciences. Aylesbury: Intertext.

Kirk, J. \& Miller, M. L. (1991). Reliability and validity in qualitative research. Newbury Park, CA: Sage.

Littlejohn, S. W. (2002). Theories of human communication $\left(7^{\text {th }}\right.$ ed.). Belmont, CA: Wadsworth Thomson Learning.

Matthews, G. (2000). Global culture/Individual identity: Searching for home in the cultural supermarket. London: Routledge.

Mokros, H. B. (1996). Introduction: From information and behavior to interaction and identity. In H. B. Mokros (Ed.), Interaction and identity: Information and behavior (Vol. 5, pp. 1-22). New Brunswick, NJ: Transaction Books.

Rushdie, S. (1991). Imaginary homelands. London: Granta.

Rutherford, J. (1990). A place called home: Identity and the cultural politics of difference. In J. Rutherford (Ed.), Identity, community, culture, difference (pp. 9-27). London: Lawrence and Wishart.

Smith, A. (1990). Towards a global culture. Theory, Culture \& Society, 7, 171-191.

Weeks, J. (1990). The value of difference. In J. Rutherford (Ed.), Identity, community, culture, difference (pp. 88-100). London: Lawrence Wishart.

Wimmer, R. D. \& Dominick, J. R. (2006). Mass media research: An introduction, (8 ${ }^{\text {th }}$ ed.). Belmont, CA: Wadsworth-Thompson.

Woodward, K. (2003). Introduction. In K. Woodward (Ed.), Identity and difference (pp. 1-6). London: Sage.

\section{Biography}

Niranjala D Weerakkody (Ph D, Rutgers U, NJ, USA) is a Senior Lecturer in Media and Communication at Deakin University. She teaches qualitative and quantitative research methods at both undergraduate and postgraduate levels, in addition to units in media effects and organizational communication. 